\title{
WHAT AND HOW MUCH IN HIGH SCHOOL CHEMISTRY.
}

\author{
By Fredus N. Peters,
}

Central High School, Kansas City, Mo.

No science, perhaps, occupies a broader field than does that of chemistry. The man who has spent years of investigation in this line of work and who is able, therefore, to hold within his mind's eye a paoramic view of a large part of the field, sees so much of wonderful interest and fascinating beauty that he is at a loss to know just what portion to explore with a class of beginners.

Before he can do much toward attempting a solution of the problem before him he must decide something as to the purpose of the school in which he is engaged. The high school, for example, has often been referred to as "the people's college"; by many universities, however, it is regarded solely as a means of prepaning students for entrance to their courses.

If we accept as true the statistics of our school men who have studied the matter we learn that from 25 to 50 per cent of the high school graduates enter college. Some schools may occasionally send a higher percentage than this, but such is not the case over the country as a rule. Even 20 per cent, however, when we consider the probable character of that number, would deserve consideration; and if a reasonable portion of that number need chemistry for college entrance or will be materially benefited by a good high school course in chemistry, as teachers of that subject we should carefully consider the matter.

On the other hand the large portion of our students close their school days when they receive their high school diploma. This large majority therefore also demands earnest consideration.

Now it must be conceded that there are many things of value to the student who expects to continue the subject, which might well be neglected by those who will take only the first year. For example, the prospective college student may well be looking toward much of the theory which is full of charming interest, and toward analytical chemistry; and the experimental part especially, of his first year work should keep these objects in view.

The general student, on the other hand, might omit such experiments as lead to qualitative analysis and much of the theo-

${ }^{1}$ Read before the Physics and Chemistry Section of the Central Association of Science and Mathematics Teachers, in St. I,ouis, Novem ber 30, 1907. 
retical, and emphasize that part of the science which deals with the practical applications to everyday life.

Granted that such a flexible course as this is desirable, is it possible to carry it out in practice? Without having attempted it, possibly I may be pardoned for theorizing upon a subject which as far as I know has never been tried by anyone. It is probable that in all the smaller high schools the number preparing for college would be so small that it would be impossible to give them a course in chemistry especially adapted to their future work. In the larger high schools with 100 to I50 taking chemistry there would probably be a sufficient number of college preparatory students to form one good class in chemistry; but judging from my own experience, it would be nearly impossible to get all these together into any one hour of the day. Assuming this as possible, however, would it be worth while attempting it? I confess I do not know and should like the opinion of others. It depends, so it seems to me, very largely upon the university man to whom the student shall go for his first college work in chemistry. If he is to be put into a class, most of whom have never been exposed to chemistry, and be compelled to do again even a considerable portion of what he did in the high school (and this will of necessity be if he has had a good stiff course in the high school) it is altogether probable that he will never become an enthusiastic student in chemistry, for very few really enjoy marking time very long.

It is probable, therefore, that we shall be compelled to offer a compromise course in high school chemistry-a course suited largely to the student who will have but the one year and yet with sufficient of the theoretical and analytical that the prospective college student may be prepared to carry freshman chemistry which presupposes some knowledge of the subject.

With this much settled or assumed as settled, the greater task is still before us. As already stated, the field is so enticing that it is a serious question what shall be included, and what omitted. For years there has been a tendency to add more and more. First came the addition of the laboratory course, now recognized as a necessity; then to this which has been almost entirely qualitative there was added a greater or less number of quantitative experiments; then came the development of several new theories, various new manufacturing processes, and within the last two or three years a demand for a considerable amount of organic work, including the paraffins, their hologen derivatives, acids, alde- 
hydes, alcohols, and ethers; the olefins, including a long list of acids more or less closely related--lactic, malic, oxalic, tartaric, citric, etc., and their salts; the glycerins, their ethers, fats, oils and soap; the saccharids, including the sucroses, glucoses, amyloses; dextrin, and cellulose; benzene and its derivatives, phenol, aniline, nitrobenzene, picric acid, acid and aldehyde derivatives, and the homologues of benzene, toluene, cinnimene, naphthalene, anthracene, alizarin, and purpurin; the terpenes, turpentine, camphor, nicotine, caffeine, cocaine opium, cinchona, strychnine, pyradine, and many others of which these are but samples. I also find in some of the newer books a chapter on animal or physiological chemistry with a study of digestion, fermentation, the blood, casein, albumen, the gelatins, etc. And this is not all; when the student has accomplished all this, there is still time for a pretty good course in qualitative analysis, and all within the usual nine or ten months of the high school year!! I know a lady in our city who told me her son, who was preparing for one of our great Eastern universities, had done five years' work in modern and ancient languages, most of which he was taking for the first time, besides the usual amount of English and mathematics, all within the space of ten months. At our high school this same boy was with difficulty induced to make I2 yearly points in three years' time. The ability of some teachers to stimulate their students is surprising. I have longed for it; I have sighed for it; I have almost prayed for it, but it has never come, and I have concluded such teachers are born and not made. I am trying as hard as possible to forget that this is true; for, realizing my utter inability to accomplish such results I am forced to the conclusion that I am fast becoming a back number, and will soon be laid upon the shelf to await the resurrection day of those chemists who have been tried and found wanting.

Gentlemen, I believe in doing well what we do. I would much prefer to spend seven or eight months upon the non-metallic elements, with the theories and quantitative experiments which naturally find a place there, and teach that WELL, than to spend four months there, three or four upon the metals, and the balance of the year upon organic compounds and qualitative analysis. With such an intensive course, I believe the student would be vastly better prepared to pursue his work in college with credit to the school from which he comes and with some assurance of success. Let us quit spreading out, and put a little thicker cov- 
ering on what we do. Let us settle upon some things as essentials and urge every one to do these thoroughly.

To decide what are essentials, however, is easier said than done. Ten years ago, I am sure I knew exactly what should be taught and just how to teach it. To-day I fear I have lost some of that serene assurance and am sincerely longing for some Moses with divine inspiration to lead us to a land of promise. We are agreed, however, I think, that a certain amount of quantitative work must be required. As chemistry never became a science till the balance was applied to the verification of its truths, so the student never learns accuracy of manipulation, nor appreciates the care necessary for success till he has done considerable quantitative work. In our laboratory, if you will pardon the reference, we have for several years required the following, with more or less variation from year to year.

Amount of water of combination in magnesium sulphate, alum, etc.

Per cent of Oxygen in Potassium Chlorate.

Weight of a Liter of Oxygen.

Displacing Power (Equivalent of $\mathrm{Fe}, \mathrm{Al}, \mathrm{Mg}, \mathrm{Zn}$ ).

Recovery of. $\mathrm{MnO}_{2}$ and Potassium Chloride in Oxygen Work.

Preparation of Acid and Normal Salts.

Per cent of Carbon Dioxide in Carbonates.

Weight of a Liter of Carbon Dioxide.

Law of Definite Proportions (Two methods).

Equivalent (Combining Weight) of Copper.

Titration of Acids and Alkalies.

- Molecular Weight of Sulplftur Dioxide.

Equivalent of Zinc (Combining Weight).

Equivalent of Lead (Combining Weight).

Estimation of Iron with Potassium Permanganate.

This gives about fifteen quantitative experiments, besides a few, such as the electrolysis of water and the synthesis of it by the eudiometer, and with hydrogen passed over Copper oxide, made in the lecture room by the instructor. If I may judge from some texts others may attempt in some cases more than this. Whether this is enough I am not prepared to say. However, as a rule it has seemed to me that students really enjoy those experiments which demand an accuracy and nicety of manipulation better than most anything else of their first year work. It is true that such as are inclined to be careless in their weighings, and whose results, therefore, are so far wrong as to necessitate a repetition, do not like quantitative work; but we are not to base 
our conclusions of its value upon anything they may say. At first students who have not had physics are worried more or less by the application of Boyle's and Charles's Laws, aqueous tension and the like in correcting gas volumes, but it is not long until they are able to handle these problems intelligently and with pleasure.

Equations Not Theoretical.- I believe it is important also after the idea of the equation has been developed that some work should be done to fix firmly upon the mind of the student the fact that equations are experimental and not theoretical. Exercise what care I may, use every precaution possible, I still find a strong tendency among students to want to "work out" on paper the equation, regardless of what their experiment has revealed. We have not done as much of this, I believe, as we should; yet it would be a very easy matter to arrange a series of simple experiments keeping this object in view, and I am not sure but that it would be worth while. Beginning with the simplest or those most self evident to the student we have used the following for this purpose.

Electrolysis of Water.

Synthesis of Water by Copper Oxide and Hydrogen.

Decomposition of Water by Sodium.

Decomposition of Sulphuric Acid by Zinc.

Preparation of Oxygen from Potassium Chlorate.

Preparation of Nitrous Oxide.

Decomposition of heavy Metallic Nitrates.

Preparation of Chlorine from Salt.

In some of the above we have not used methods that would satisfy in every particular the nice discrimination of the skilled chemist, but as a rule the course pursued is sufficiently accurate for the beginner and serves to assist in impressing the fact, with the aid of the instructor holding a sledge hammer over the student, that equations are really the outgrowth of quantitative experiment.

IMPORTANT THEORY.-There are some theories which it seems to me must not only be studied in the class room, but emphasized also in the laboratory. Among them I would mention:

Ionization.

Mass Action.

Reversible Equations.

Hydrolysis.

Natural Grouping of Elements. 
A large number of experiments occurring from time to time may be used to illustrate the first of the above. It is my experience, however, that with conscientious endeavor both in the lecture room with a variety of experiment there, and equally persevering attempts in the laboratory to teach this theory and some of its beautiful applications, the results have been far from satisfactory; and it is my firm belief that comparatively few of the photographic plates exposed to this treatment and those only the most sensitive show any clear prints when the final test comes. Whether the attempt should be abandoned with the mixed classes we have and leave it for the prospective college student to get when he may later, I am not attempting to say.

Mass Action and Reversible Eguations.-These naturally go together, and a variety of simple experiments may be used to illustrate. For example, the precipitation of zinc as Sulphide from zinc acetate and from zinc sulphate, the latter with varying amounts of sulphuric acid added to the original solution before precipitation begins; (2). The conversion of antimony chloride into the oxychloride and the reverse; (3) The conversion of bismuth nitrate into the subnitrate and reverse. These and others of similar nature are interesting experiments and are not only enjoyed but understood by the majority of the students.

Hydrolysis cannot well be omitted. The student finds aluminum precipitating as hydroxide by the use of either a carbonate or sulphide. He studies tre chemical action of alum in baking powders; he sees the action of sodium carbonate upon ferric chloride, the preparation of basic lead carbonate when sodium carbonate is added to the solution of a lead salt, and various others. These are but examples of many experiments of this character which demand explanation. With the student on his guard, working slowly and watching carefully for results he will see and understand something of the many applications of this principle. For a real appreciation of it, however, he must know something of the ionic theory.

A number of experiments may be used to illustrate some of the facts brought out in the periodic table. If we study the oxides of zinc, aluminum, arsenic, and sulphur, as to their acidic and basic properties, we learn not only the fact of increasing acidity from left to right, but also the double character sustained by various elements occupying positions near the center of the table. If we 
study the oxides of the elements of the nitrogen group, we learn experimentally the decreasing acidity of them as their atomic weights increase; so in variots other experiments which we really perform we may make applications bearing on the facts set forth in the table.

In mentioning the above I have given the experimental side only, but. I have left you to infer that all this is stupplemented strongly in the lecture room either by repetition of some of the experiments, the addition of others, or in such other ways as necessity seems to demand.

LAws.--In preparing for this occasion I have taken time to look over again some of the elementary texts now before the public, and I find the following laws discussed at greater or less length in some or all of them:

Conservation of Matter.

Constant Proportions.

Boyle's.

Charles's.

Avogadro's Hypothesis.

Osmosis.

Definite Proportions.

Multiple Proportions.

Dulong and Petit's Law, and possibly some others.

Whether we can serve up this entire bill of fare without bringing about many cases of serious mental gastritis, I am not sure. I have never felt that I was equal to the task, hence have emphasized strongly by experiment and class study only about half of them. I am not saying anything, however, about what others can do-I only know my own limitations.

Thus far in giving the content of the high school chemical course I have mentioned. largely those phases which I presume will be most necessary in preparing the student who expects to continue the subject in college. The other portion-the majority - under present conditions will be compelled to take this dose. as well as those who want it or must have it; we must make strong effort therefore to present it in such a way that it will be as little objectionable as possible. In fact, I believe a good deal of it may be largely sugar-coated and yet be fairly efficacious for all. More than this we must provide for the general student equally well. This must come, it seems to me, through the practical phases of the stbject. These are not only many but interesting. Among them I wotld mention: 
Refrigeration.

Explosives.

Bleaching cloth, feathers, fruits, silks, and straws.

rlluminating gases; coal, acetylene, water and pintsch.

Glass and its varieties.

Matches.

Soaps.

Cement work and plaster.

Softening of hard water.

Clarifying sugar.

Simple photography.

Electro-plating.

Baking powder and Soda biscuits.

Clarifying eity water supplies.

Galvanized Iron and Tin.

Type-metal, shot, solder.

White lead, Chrome yellow, Paris green, etc.

Pig iron and Steel.

To entmerate this seems like a formidable array, yet it may be classified and accomplished with much greater ease than would seem possible.

Another suggestion I make in behalf of the general student.

We have found among our classes a very great interest taken in the preparation and purification of various compounds, for example, those of potassium from wood ashes. This is work which comes up naturally during the last third of the year or after we begin the study of the metals. If the students are encouraged to preserve specimens of what they prepare, and are required to know what they are doing, they not only become wonderfully interested in the work, but are greatly benefited as well.

Before closing there is one other matter I wish to suggest, and it is one I have thought over for some time. Would it be possible, or if possible would it be advisable at the end of the first half year in chemistry to divide the classes in such a way that those who are preparing for college and the stronger students might be put together and given a good stiff course the remainder of the year; the other division to be offered a course in applied or domestic chemistry, taking up considerable more in detail than we do now the practical phases of the subject? In some ways the plan appeals to me. "For example, some three years ago, in our study of bread and biscuits, I suggested the plan of using soda and hydrochloric acid as a leavening power instead of ordinary baking powder. Not only were the girls much interested, but the boys as well. In many instances where they could not induce 
their mothers or the domestics at home to make the experiment, they went into the kitchen and did the work themselves, both boys and girls. For three weeks we had brought in before school every morning not only biscuits, but muffin and layer cakes, showing many very excellent results. I kept a tabulated report of each case, noting kind of flour used, shortening, whether mixed with milk or water, and such other data as I thought might be of interest or value in judging of the results. Such a course would mean an immense amount of work for the instructor, as it would almost have to be constructed from the ground up. Still it might pay.

The time allotted me is too short to present this subject in any way other than fragmentary and suggestive. What I have said has been offered with the hope that it may lead to a general discussion before this body and result in some conclusions to which we may hold fast. There are some things in connection with the teaching of chemistry regarding which I have firm convictions; there are others of which I do not feel sure. May we take counsel together and in the end find much that will be helpful to us through all time.

\section{FLECTRIC SPARK PRODUCED WHEN ICE IS FORMED.}

Dr. T. L. Phipson, in his book "Phosphorescence," London, 1862, page 29, publishes the following suggestive paragraph:

A most interesting production of light was observed and published ("Journ. des Sc. Physiques et Chiniques," de M. de Fontenelle) by Professor Pontus, in 1833, who showed that a vivid spark is produced when water is made to freeze rapidly. A small glass globe, terminating in a short tube, is filled with water, the whole is covered with a sponge or cotton-wool imbibed with ether, and placed in an air-pump. As soon as the experimenter begins to produce a vacuum, the ether evaporates, and the sponge or cotton-wool dries, the temperature of the water descends rapidly. But some instants before congelation takes place, a brilliant spark, perfectly visible in the daytime, is suddenly shot out of the little tube that terminates the glass globe. M. Pontus has repeated the experiment often, and says that the production of this spark is a sure sign that congelation is about to happen.

The Editor has not been able to obtain the original memoir by Professor Pontus, but if there be no mistake in this experiment and observation then we have here a very plausible explanation of the origin of the lightning that attends hail and thunderstorms in the summer and equally so of the gentler electric discharges attending thunderstorms in winter-possibly also of the still gentler auroral discharge. Will not someone investigate this subject anew?-C.A., in Monthly Weather Review, July, 1907, page 317 . 